\title{
Development of lifetime warranty policies and models for estimating costs
}

\section{Gopinath Chattopadhyay and Anisur Rahman}

School of Engineering Systems, Queensland University of Technology, 2 George Street P.O. Box 2434, Brisbane, Qld. 4001, Australia

\begin{abstract}
In today's fiercely competitive products market, product warranty has started playing an important role. The warranty period offered by the manufacturer/dealer has been progressively increasing since the beginning of the 20th Century. Currently, a large number of products are being sold with long-term warranty policies in the form of extended warranty, warranty for used products, service contracts and lifetime warranty policies. Lifetime warranties are relatively a new concept. The modelling of failures during the warranty period and the costs for such policies are complex since the lifespan in these policies are not defined well and it is often difficult to tell about life measures for the longer period of coverage due to usage pattern/maintenance activities undertaken and uncertainties of costs over the period. This paper focuses on defining lifetime, developing lifetime warranty policies and models for predicting failures and estimating costs for lifetime warranty policies.
\end{abstract}

\section{Introduction}

Warranty is a legal obligation of the manufacturer or dealer in connection with the sale of the product. Warranties define the responsibility of the manufacturer/dealer in the event of early product failure [1]. To the customers, longer warranty terms signal higher reliability and a peace of mind. On the other hand, to the manufacturer, the expected warranty cost generally increases with the increase of duration of warranty cover. Moreover, the longer the coverage period the greater is the risk due to uncertainty of failure mechanism and costs. Due to the fierce competition in the market and the customer demand, the warranty period offered by the manufacturer/dealer has been progressively increasing since the beginning of the 21st Century [2]. Some of the car manufacturers have been offering five year bumper to bumper warranty for the cars and six year warranty for certain parts. A number of producers of electrical and electronic goods have also started offering lifetime warranties for their products. However, lifetime is not defined clearly in many cases. - 'Sealevel Systems Inc. (http://www.sealevel.com/about.asp)' warrants their I/O products to conform and perform in accordance with published technical specifications to be free from defects due to materials and workmanship for the lifetime. "Lifetime" is defined as seven years after Sealevel discontinues manufacturing the product. The warranty period would, therefore, be technically around 10 years from the date of purchase. 
- Celestron warrants their binocular to be free from the defects of materials and workmanship for its usable lifetime (http://www.celestron.com).

- SOG Corporation Limited, a manufacturer of tools and blades provides warranty for their product as long as the customer uses the products for his/her own purpose and the coverage terminates with resell or transfer of the product (http://www.sogknives.com).

These examples show that the measurement of a product's useful life (lifetime) varies from product to product and depends on the manufacturer's intention. There is a need to develop a framework for lifetime and new policies useful for industries, and to develop models for predicting failures and estimating costs for such policies.

Modelling failures over the lifetime and estimation of costs for lifetime warranty is complex due to the uncertainties of usage and level of maintenance during such uncertain periods, and the prediction of costs due to limited failure cost data for modelling purposes.

This paper examines the development of lifetime warranty policies and developed models for predicting failures and estimating costs for offering those policies.

The outline of the paper is as follows. Section 1 provides an introduction of lifetime warranties. In Section 2, the role of those warranties is discussed. In Section 3, a framework for long-term warranty policies is developed. A taxonomy for lifetime warranty policies is proposed in Section 4. Mathematical models are developed for predicting failures and estimating costs in Section 5. Numerical examples are used for illustrative purpose. The contribution of this research and scope for future research is discussed in the final section.

\section{Roles and concept of warranty}

Under the contractual agreement, a manufacturer/dealer is obliged to rectify defects or failure of products due to design, manufacturing and quality assurance problems [1].

Warranties are important to the customer, the manufacturer/dealer, insurer and the public policy makers. It plays a protective role for the customer by acting as an insurance against early failure of an item due to design, manufacturing or quality assurance problems. It also acts as a source of information about product quality and reliability. Warranty protects the manufacturer against any damage/failure of the product due to misuse or abuse by the customer. It plays the promotional role to signal the quality of products to the potential customers. It also acts as a powerful advertising tool for a manufacturer/dealer to compete effectively in the market place. Stakeholders of warranty policies are presented in Fig. 1. 


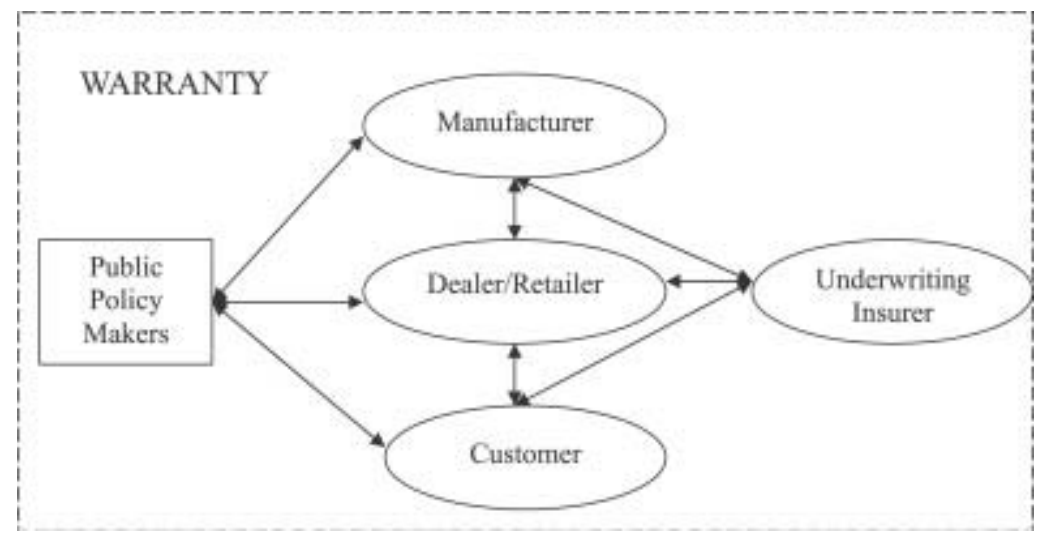

Fig. 1. Stake holders in warranty policies and servicing warranty claims.

At present most of the manufacturers or dealers use insurance companies to underwrite the costs incurred due to servicing warranty claims. Manufacturers/dealers pay a premium to insurers. It is the insurer's responsibility to check all claims and act according to the terms of the policy.

Product warranty has received huge attention from researchers from many different disciplines dealing with a diverse range of issues. These include historical, legal and legislative, economic, behavioural, consumerist and engineering issues. Other areas include stochastic statistical modelling and analysis, operations research, accounting, marketing, management, societal and many others. Each discipline has analysed warranties from different angles. Djamaludin et al. [3] lists over 1500 papers on warranties which are classified into different categories. Some of the issues related to warranties are discussed in detail in [1] and [4]. Singpurwalla and Wilson [5] addressed game theoretical aspects of warranty problems. The brief review of the literature shows that only a very few researchers have worked in the area of lifetime warranty.

\section{Long-term warranty policies}

Long-term warranties offered by manufacturers/dealers include extended warranty, warranty for used product, long-term service contract and lifetime warranty policie[6] and is shown in Fig. 2. 


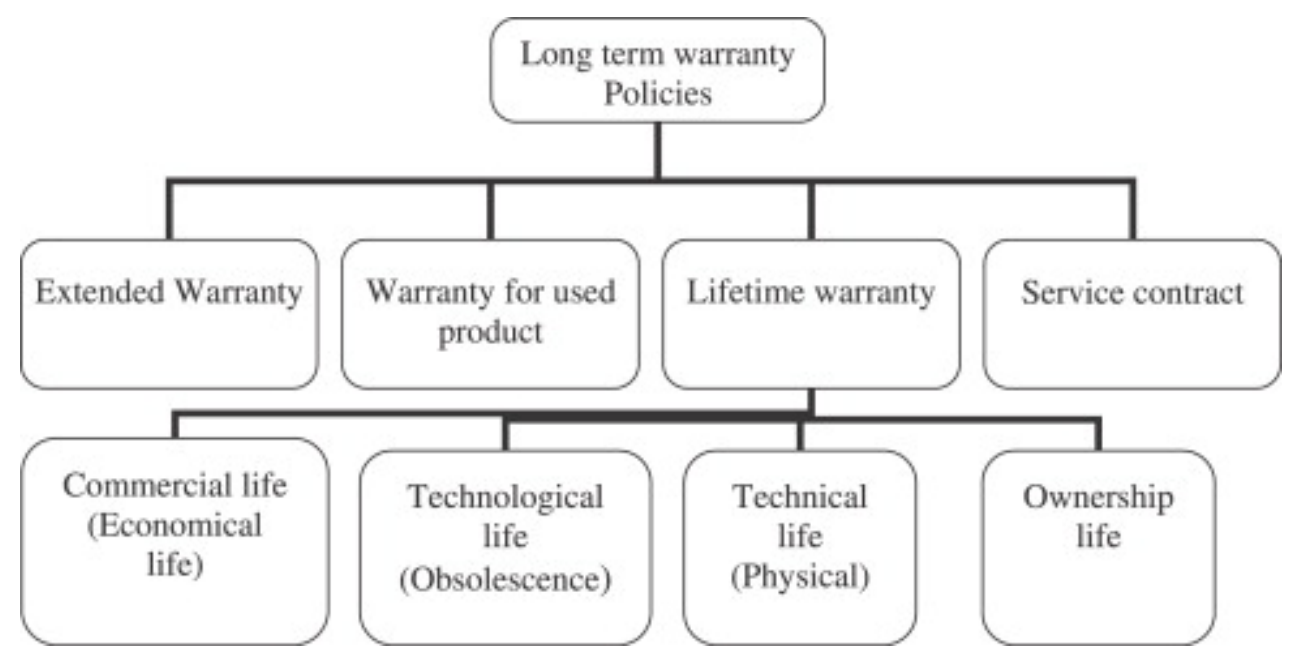

Fig. 2. A framework for the long-term warranty measure [6].

\subsection{Extended warranty}

The base warranty is an integral part of product sale and is factored into the sales price [2]. An extended warranty is for coverage beyond the base warranty which is an obligation of responsibility assumed by the manufacturer or dealer for further service beyond the base warranty period for a premium. Consumers who desire extra protection can purchase this additional coverage. These types of coverages are sold by the manufacturer, dealers or by third parties. The presence of an independent insurer/underwriting for an extended warranty can change the manufacturer's warranty and pricing policies which can ultimately have an impact on a manufacturer's profits and consumer's purchasing intention [7].

\subsection{Warranty for used/second-hand product}

Warranty for used/second-hand product now being offered by dealers in some special cases can be considered as an extended warranty. Details could be found in [8], [9] and [10].

\subsection{Service contracts}

For expensive and complex equipment/systems with longer useful life such as a power generation plant, railway system, the owner of the equipment/system needs expertise and specialised maintenance facilities to carry out effective maintenance [11]. In these cases, it is more economical for the owner to contract out the maintenance actions to an external agent instead of carrying out in-house maintenance. The external agent could be the manufacturer or an independent third party [12].

\subsection{Lifetime warranties}


Lifetime warranties are covered for the life as defined in the warranty policy. In general, it can be defined as the manufacturer/dealer's commitment to provide free or cost sharing repair or replacement of the sold product in case of failure due to design, manufacturing defects or quality problems during the useful life of the product or the buyer's ownership period.

"Lifetime" is defined in different ways by various providers. For example, a warrantor of an auto muffler may intend "lifetime" to be for the life of the car. In this case, the muffler warranty would be transferable to subsequent owners of the car and would remain in effect throughout the car's useful life. However, a "lifetime" warranty can cover as long as the original purchaser of the muffler owns the car. Finally, "lifetime" can be as long as the original product survives.

Termination of lifetime warranty may arise due to technological obsolescence, design modifications, or change of component. For example, the lifetime warranty of a picture tube will cease if the TV unit is found to be out of service due to the failure of other critical components because of wear out or accident [13] or, the whole system is declared obsolete due to technological transformation such as black and white televisions being replaced by colour televisions (in 1980s) and by the LCD and plasma televisions (in 2000s). Therefore useful lifetime can be defined as the lifetime of the product in the market and can be assumed to be terminated in some finite, random time horizon. Outdated technology is not covered by lifetime warranty. The life term is proposed to be defined in any of the following ways:

- Technical life/physical life - the period over which the product might be expected to last physically (up to the period when replacement or major rehabilitation is physically required).

- Technological life - the period until technological obsolescence dictating replacement due to the development of a technologically superior alternative.

- Commercial lifeleconomic life - the period over which the need for the product exists, the period until economic obsolescence dictates replacement with an alternative.

- Ownership life/social and legal life - the period until customer's desire or legal ownership is retained or change of ownership occurs.

However, a reasonable assumption of lifetime warranty is that it does not cease before the statutory warranty period ends and it does not exceed the technical or physical life of the product. Changes of ownership data for products such as cars can be available from transport department data registering the resale of cars. Other categories are not easily predictable and can be estimated based on the time interval of new models/technologies and cost disadvantage of operating a product for a longer period when new generation products are more competitive in terms of operating cost or ownership changes as log-book. The distribution of ownership change can be modelled by using the resale age of new products. 
The terms (e.g. coverage) for these policies can vary from item to item and can depend on the customer's and manufacturer's risk preferences. A taxonomy of these policies is proposed in the following section.

\section{Taxonomy for lifetime warranty policies}

Taxonomy for the different types of lifetime warranty policies is proposed in Fig. 3.

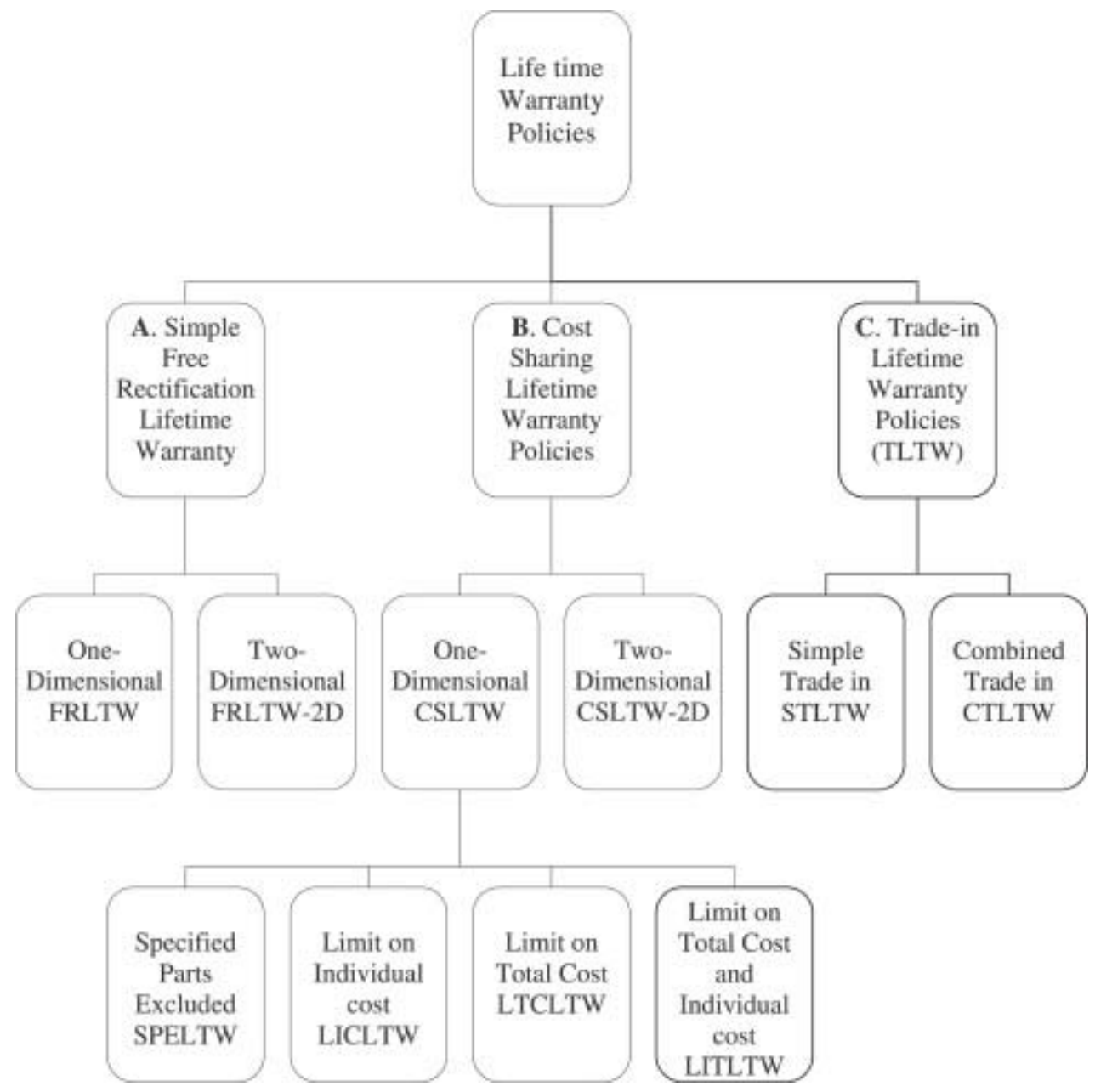

Fig. 3. Taxonomy for lifetime warranty policies.

New lifetime warranty policies proposed in this paper can be divided into three main groups. These are: Group A, Free Rectification Lifetime Warranty (FRLTW) policies; Group B, Cost Sharing Lifetime Warranty (CSLTW) policies; and Group C, Trade-in with Lifetime Warranty (TLTW) policies. FRLTW and CSLTW are again divided into two sub-groups based on the dimensions of the coverage, i.e. a one-dimensional policy covers only the age of the product. Whereas, two-dimensional policy considers more than one dimension such as the age and usage of the product. Any failures within the age or usage are rectified according to the terms of the policy. Here, we will confine our attention to one-dimensional policies and items sold individually. 
Group C 'Trade in' policies are divided into two groups. These are Simple Trade-in Lifetime Warranty (STLTW) and Combined Trade-in Lifetime Warranty (CTLTW).

\subsection{Lifetime warranty policies}

The main complexity in this area is the uncertainties with useful life (lifetime) and subsequently the coverage periods. Another complexity is the uncertainty of servicing costs over longer uncertain periods. A brief description of all these policies is as follows:

\subsubsection{FRLTW policy}

Policy 1. FRLTW (one-dimensional) with no cost to buyer/customer: Under this policy the manufacturer/dealer takes the responsibility to rectify all defects and failures of the sold product due to design or manufacturing or quality control problems over the defined lifetime of the product. Rectification can be a replacement, repair or in some cases refund. Unlike normal warranty, the coverage period for a lifetime warranty is uncertain and randomly variable.

Policy 2. FRLTW on both age and usage (two-dimensional case) with no cost to buyer/customer [FRLTW-2D]: Under this policy the manufacturer/dealer rectifies all defects and failures of the sold product due to design, manufacturing or quality control problems over the age and usage of the product whichever comes first within defined lifetime of the product. Rectification can be a replacement or repair or in some cases a refund. Here the coverage terminates at an age or usage due to the ownership change, technological obsolescence, useful or commercial reason.

\subsection{CSLTW policies}

Under this policy, the customer and the manufacturer/dealer share the repair cost over the uncertain coverage period. The basis for the sharing can vary as indicated below. In line with [9], we propose four one-dimensional CSLTW policies. These are: Specified Parts Excluded Lifetime warranty (SPELTW), Limit on Individual Cost Lifetime Warranty (LICLTW), Limits on Total Cost Lifetime Warranty (LTCLTW), and Limit on Individual and Total Cost Lifetime Warranty (LITLTW). These policies are described briefly as follows:

Policy 3. SPELTW: Under this policy, the components of the product are grouped into two disjointed sets, Set-I (for inclusion) and Set-E (for exclusion). The manufacturer/dealer rectifies failed components belonging to Set-I at no cost to the buyer over the defined lifetime of the product. The costs of rectifying the failed components belonging to Set-E are borne by the customer (note: the rectification of failed components belonging to Set-E can be carried out either by the dealer or a third party).

Policy 4. LICLTW: Under this policy, if the cost of a rectification on each occasion is below the limit $c_{\mathrm{I}}$, then it is borne completely by the manufacturer/dealer and the customer pays nothing. If the cost of a rectification exceeds $c_{\mathrm{I}}$, the buyer pays all the costs in excess of $c_{\text {I }}$ (i.e. cost of rectification $-c_{\mathrm{I}}$ ). This continues until the termination of warranty based on defined lifetime. 
Policy 5. LTCLTW: Under this policy the manufacturer/dealer's obligation ceases when the total repair cost over the lifetime exceeds $c_{\mathrm{T}}$. As a result the warranty ceases at an uncertain lifetime or earlier if the total repair cost, at any time during the lifetime, exceeds a prefixed cut off cost $c_{\mathrm{T}}$. Here, the warranty coverage is uncertain not only for uncertainty in exceeding total cost limit but also for the uncertainty of lifetime as defined in the policy.

Policy 6. LITLTW: Under this policy, the cost to the manufacturer/dealer has an upper limit $\left(c_{\mathrm{I}}\right)$ for each rectification and the warranty ceases when the total cost to the dealer (subsequent to the sale) exceeds a cut off cost $c_{\mathrm{T}}$ or the termination of the product life due to the defined reasons, whichever occurs first. The customer pays all the costs in excess of $c_{\mathrm{I}}$.

\subsection{Trade in with lifetime policies}

The two types of trade in with lifetime warranty policies proposed here are as follows:

Policy 7. STLTW: Under this policy, the customer has an option to get a replacement at a reduced cost of trade-in for the used one. In this type of warranty the failed used product under warranty is repurchased by the manufacturer/dealers. The repurchased price would be a proportion of the original purchased price depending on the age of the product, i.e. the repurchased price (trade in price) $P_{\mathrm{t}}=P_{\mathrm{o}}(a / E(L))$, where $P_{\mathrm{o}}$ is the original purchased price and $a$ is the age of the product at the time of trade in. $E(L)$ is the expected lifetime of the product. However in real life trade-in price can be negotiable.

Policy 8. CTLTW policy: Under this policy the failed or defective product is rectified free of cost to the customer/buyer up to a certain time $w$ and if the product fails any time beyond $w$ over the rest of the lifetime the failed product is repurchased by the manufacturer/dealer at a reduced price (see Fig. 4). Clearly, under this policy the coverage time is divided into two terms. These are: (1) up to $w$, the warranty condition is similar to that of the free rectification warranty and (2) from the age $w$ to the termination of lifetime follows the simple lifetime trade-in policy as shown in Fig. 4.

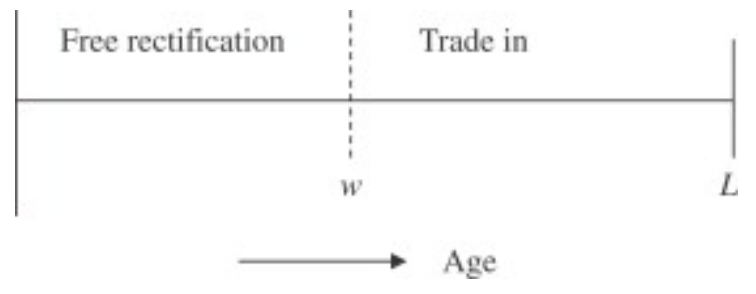

Fig. 4. Combined trade-in policy. 


\section{Modelling costs for lifetime warranty at system level}

Most real life products can be treated as a system comprising number of components and failures are modelled at the system or sub-system level.

We assume cumulative failure distribution of the product is modelled as $F(t)$ with density function $f(t)=\mathrm{d} F(t) / \mathrm{d} t$ and the product failure intensity function is modelled as

(1)

$$
A(E)=\frac{f(b)}{(1-F(b))} \text {. }
$$

\subsection{Assumptions}

- Item failures are statistically independent.

- Item failure, in a probabilistic sense, is only a function of its age.

- The time to carry out a rectification action by repair or replacement is negligible compared to the mean time between failures and this time is ignored.

- An item failure results in an immediate claim and all claims are valid.

\subsection{Notations}

We use the following notations for the purpose of this paper:

$\alpha$ increasing rate of cost due to increase of cost of material, labour, inflation and other factors

$\beta$

shape parameter of product failure distribution

$\delta$

discounting rate (annuity)

$\eta$

product characteristic life parameter

$\lambda$

inverse characteristic life parameter which is given by $\lambda=1 / \eta$ 
parameter for the truncated exponential distribution used in the life distribution of products

$\mu_{a}$

mean lifetime coverage

$\Lambda(t)$

intensity function for product failure

$L$

lifetime warranty coverage period

$a$

condition of coverage

$N_{i}$

year $i$, where $i=1,2,3, \ldots, L$

$H(a)$

distribution function of the lifetime coverage (useful life)

$h(a)$

density function associated with $H(a)$

$l$

lower limit of $a$

$u$

upper limit of $a$

$\bar{c}$

expected cost of each rectification over the lifetime (system level)

$\gamma$

parameter for rectification cost when distributed exponentially.

\subsection{Modelling failures and costs for FRLTW}

\subsubsection{Modelling product failures for FRLTW policy}


Here, the failure rate of product is an increasing function of age (as assumed). Since the number of failed components rectified at each failure is very small relative to the total number of components in the item, the rectification action can be viewed as having a negligible impact on the failure rate of the product as a whole. In other words, the failure rate after a repair is nearly the same as that just before the failure. Such a repair action is called a minimal repair [14]. This type of failure can be modelled as the Non-Homogeneous Poisson's Process (NHPP). In this case $\Lambda(t)$ is the failure rate associated with the failure distribution for the product. When product failure is distributed as $F(t)$ following NHPP with density function $f(t)$, then the failure intensity $\Lambda(t)$ can be assumed as follows:

(2)

$F(t)=1-\exp \left(-(\lambda t)^{\beta}\right)$

and

(3)

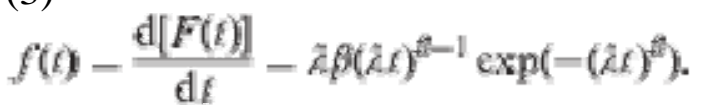

From Eq. (1), $\Lambda(t)$ is given by

$$
A(i)=\frac{f(\xi)}{1-F(\xi)}=\frac{\lambda \beta(\lambda t)^{2-1} \exp \left(-(\lambda)^{f}\right)}{1-\left(1-\exp \left(-(\lambda)^{f}\right)\right.}=\lambda \beta(\lambda)^{f-1}
$$

with the parameters $\beta>1$ and $\lambda>0$.

\subsubsection{Modelling lifetime}

Since the lifetime of the product is uncertain, the warranty coverage period $L$ is random variable (unlike basic warranty coverage, the upper limit of the coverage period is a random variable with mean $\mu_{a}$ ). Failures might occur randomly within the region $0-L$. Conditioned on $L=a$, one can model this lifetime as a random variable with a distribution function $H(a)$ with $H(l)=0$ and $H(u)=1 . l$ and $u$ are the lower and upper limits of termination of lifetime $L$ at statutory base.

$h(a)$ is the probability density function of $a$ associated with $H(a)$ and

(5)

$$
f(t i)=\frac{\mathrm{d} H(f t)}{\mathrm{d} f t} \text {. }
$$

One form of $H(a)$, which is analytically tractable, is the following truncated exponential distribution (see Chattopadhyay and Murthy [8]):

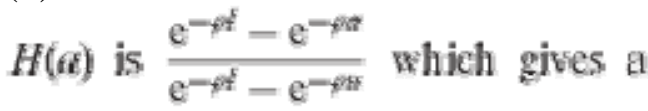

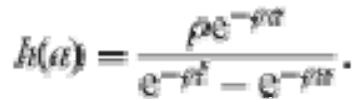

The mean value of useful life of the sold product can be expressed by 


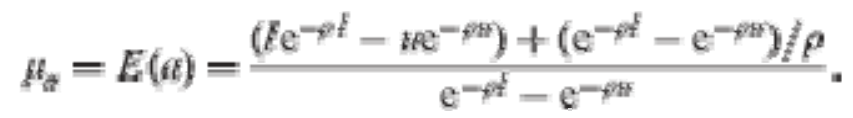

In real life distribution of lifetime coverage might not be possible to model using a particular distribution and can be modelled using probability mass function.

\subsubsection{Modelling per occasion repair cost}

The cost of each repair $C$ is, in general, a random variable because an item failure is due to the failure of one or more of its components and cost of repair or replacement varies with components. We assume $G(c)$ and $g(c)$ as the cumulative distribution function and density function of rectification costs of the product over the lifetime i.e.

(8)

$G(c)=P\{C \leqslant c\}$.

Then the expected cost of each rectification action, $E(C)=\bar{x}$, is given by

$$
E(C)=\bar{c}=\int_{0}^{\infty} \operatorname{cg}(e) \mathrm{d} e
$$

For the purpose of simplification of the model analysis, we consider a case where the cost of rectification is distributed exponentially with exponential parameter $\gamma$. This consideration is true for most of the simple products. For such case $G(c)$ is considered to be an exponential distribution so that

$G(c)=1-\mathrm{e}^{-\gamma c}$.

Then the expected cost of each rectification with cost parameter $\gamma$ is given by

(11)

$\bar{c}=[1 / \eta]$.

Moreover the cost can vary subsequently in the longer uncertain period of contract and a negotiation clause can possibly be included. For a very long product life, a cost trend and discounting factor can be included to the cost model.

\subsubsection{Modelling total expected warranty cost for FRLTW}

For products with longer lifetimes such as a car, the total warranty cost is uncertain over longer period of time due to the uncertainties of lifetime and the costs of servicing claims. This is due to increased labour and material costs, and discounting of money over time as shown in Fig. 5. 


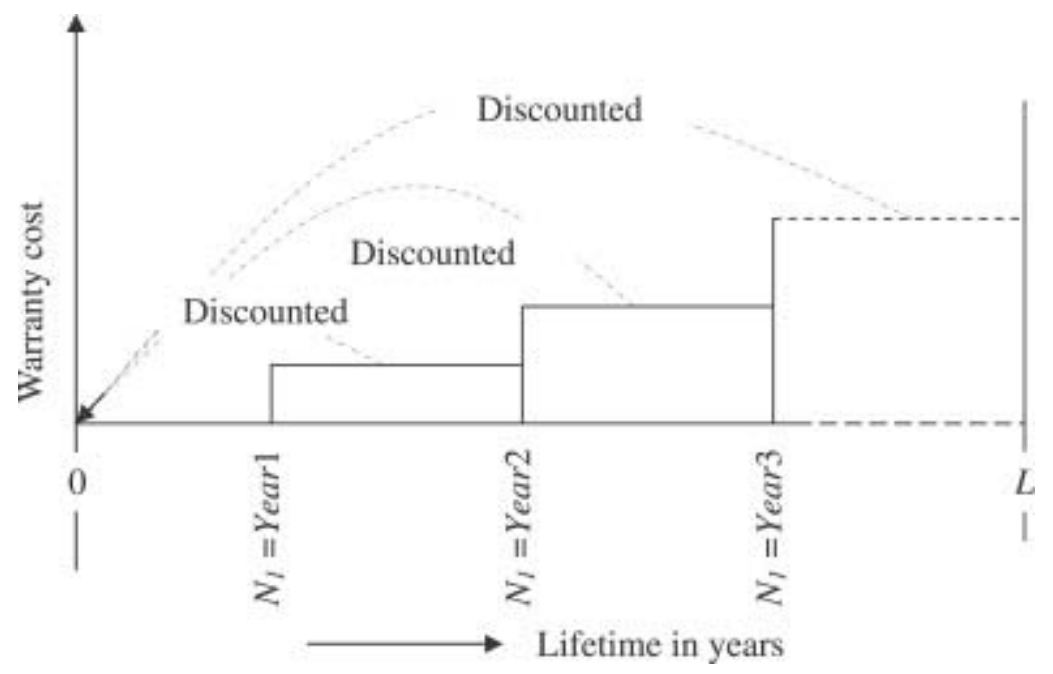

Fig. 5. Effects of discounting for warranty costs under longer coverage period.

The lifetime coverage of the product $L$ is uncertain due to the ownership change, technological obsolescence, and useful and commercial reasons.

Let the expected number of failures and the expected cost of warranty claims for year $i$ be $E\left(N_{i}\right)$ and $E\left(C_{i}\right)$, respectively. Costs of premiums are assumed to occur at the beginning of every year.

Then the present value of the expected cost for lifetime warranty can be modelled as

$$
E\left(C_{f}\right)=\sum_{t=1}^{L} E\left(N_{f}\right) E\left(C_{f}\right) P\left(N_{i}\right) \times\left(\frac{1+a}{1+4}\right)^{t-1} \text {, }
$$

where $P\left(N_{i}\right)$ is the probability that lifetime terminates at year i. $P\left(N_{i}\right)$ is a function of ownership change, technological, obsolescence, and useful and commercial life of products.

$\alpha$ denotes increasing rate of cost and $\delta$ represents the discounting rate.

For the purpose of model simplification, we assume values of both $\alpha$ and $\delta$ equal to 1 . This assumption is realistic for products with shorter lifetimes, i.e. products with a lifetime close to one year.

The total cost of warranty during the lifetime can therefore be expressed as

$E\left(C_{t}\right)=E(C) E[N(L)]$,

where $E(C)$ is the expected cost of warranty for each occasion of failure and $E[N(L)]$ is the expected number of failures over the lifetime coverage period $a$. 
Under this policy (FRLTW) the manufacturer/dealer is obliged to rectify all defects and failures of the sold product due to design or manufacturing or quality control problems over the defined lifetime.

Here, we consider the product as a system composed of a number of components. Rectification can be a repair or replacement of one or more components. Product failures are modelled as occurring according to a point process with an intensity function $\Lambda(t)$ where $t$ represents the age of the product. $\Lambda(t)$ is an increasing function of $t$ indicating that the number of failures, in a statistical sense, increases with age. As a result, $N(t)$, the number of failures over the warranty period is a random variable.

Since, the useful life of the product can be terminated at any time due to the ownership change, technological obsolescence, technical or commercial reason, the termination point of lifetime coverage can be bounded by a lower limit $(l)$ and upper limit $(u)$ at statutory base. The expected number of failures during the lifetime can be modelled using conditional probability of coverage $=a$ and then lifting the condition and limiting it between $l$ and $u$ as follows:

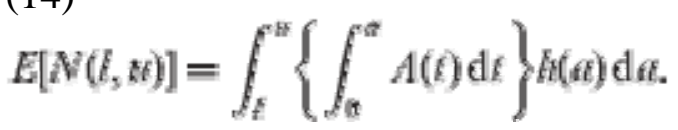

Therefore, the total cost for FRLTW due to warranty claims over the lifetime of the product can be given by

$$
\begin{aligned}
E[C(l, t)] & =E(C) E[N(l, t)] \\
& =\bar{\epsilon}\left[\int_{E}\left\{\int_{0}^{*} A(\varepsilon) \mathrm{d} \varepsilon\right\} F(\epsilon) \mathrm{d} \epsilon \varepsilon\right]
\end{aligned}
$$

or by substituting value of expected per occasion repair cost from Eq. (11):

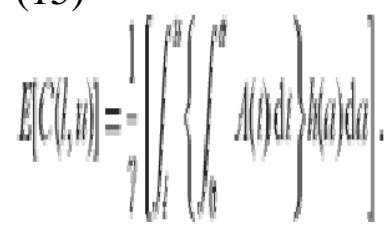

\subsection{Analysis of the cost model for FRLTW}

By substituting value of $\Lambda(t)$ from Eq. (4) in Eq. (15), the total expected cost can be modelled as

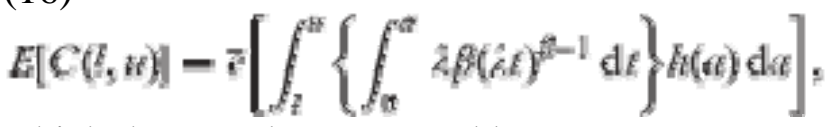

which then can be expressed by

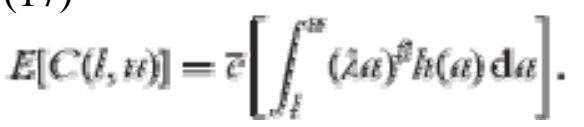

Now substituting $h(a)$ value from Eq. (6) in Eq. (17), we have 
(18)

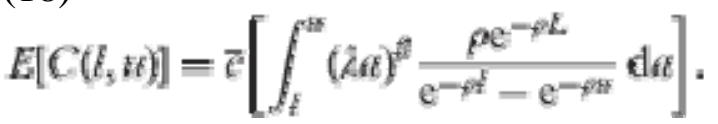

\subsubsection{Numerical example}

Let $\beta=2$ and $\lambda=0.443$ per year. This implies that the mean time to first failure is close to 2 years. Let the expected cost of each repair be $\$ 100$ (with $\gamma=0.01$ ) and let lifetime parameter be $\rho=0.4$. The expected warranty costs, $E[C(l, u)]$ for different combinations of $l$ and $u$ are shown in Table 1 .

Table 1.

Warranty $\operatorname{cost}(\$)$ to the manufacturer for lifetime free rectification (FRLTW)

\begin{tabular}{|c|c|c|c|c|c|c|c|c|}
\hline \multirow{2}{*}{$u$} & \multicolumn{8}{|l|}{$I$} \\
\hline & 0.5 & 1 & 1.5 & 2 & 2.5 & 3 & 3.5 & 4 \\
\hline 2 & 30.72 & 43.93 & 59.93 & - & - & - & - & - \\
\hline 4 & 85.70 & 109.30 & 136.85 & 167.77 & 201.50 & 237.48 & 275.15 & - \\
\hline 4.5 & 100.68 & 127.00 & 157.52 & 191.70 & 229.00 & 268.72 & 310.43 & 353.40 \\
\hline 5 & 115.63 & 144.62 & 178.02 & 215.55 & 256.33 & 299.97 & 345.75 & 393.17 \\
\hline 5.5 & 130.33 & 161.93 & 198.35 & 239.03 & 284.50 & 330.83 & 380.77 & 432.62 \\
\hline 6 & 144.63 & 178.72 & 218.05 & 261.90 & 309.77 & 361.03 & 415.12 & 471.42 \\
\hline 6.5 & 158.30 & 195.08 & 237.00 & 284.00 & 335.27 & 390.33 & 448.52 & 509.23 \\
\hline 7 & 171.33 & 210.33 & 255.83 & 305.03 & 359.68 & 418.43 & 480.07 & 545.80 \\
\hline
\end{tabular}

It shows that the warranty cost to the manufacturer/dealer increases as the lifetime increases. It also shows that the warranty cost increases as the range of lifetime increases. This implies that the longer the span of lifetime the more the number of failures and higher the cost to the manufacturer/dealer and there is a need for detailed analysis using realistic models.

\section{Conclusion}

Lifetime warranties are a relatively new concept. Different people use the measure of lifetime in different ways which results in complexities in modelling the costs of the lifetime warranty policies. 
In this paper we have proposed useful definition for life measures applicable to lifetime warranty policies. Here, we have proposed and developed a taxonomy for new lifetime warranty policies. We have developed cost models for a one-dimensional FRLTW policy and analysed the development with a numerical example.

There is huge scope for future research in this area. This includes modelling failures and costs for different types of cost sharing and trade in lifetime warranty policies, modelling failures and costs for two-dimensional policies, expected life cycle costs (LCC) for complex system with repairable and non-repairable components and provision of second-hand components used in servicing warranty claims. Other areas for future research could be modelling effects of various servicing strategies such as overhauling and preventive maintenance on the long-term warranty costs.

\section{References}

[1] W.R. Blischke and D.N.P. Murthy, Warranty cost analysis, Marcel Dekker, New York (1994).

[2] Murthy DNP, Jack N. Warranty and maintenance. Handbook of reliability engineering; 2003. p. 305-14.

[3] I.A. Djamaludin, D.N.P. Murthy and W.R. Blischke, An annotated bibliography on warranties. Product warranty handbook, Marcel Dekker, New York (1996).

[4] W.R. Blischke and D.N.P. Murthy, Product warranty handbook, Marcel Dekker, New York (1996).

[5] N.D. Singpurwalla and S. Wilson, The warranty problem: its statistical and game theoretical aspects, SIAM Rev 35 (1993), pp. 17-42.

[6] Rahman A, Chattopadhyay GN. Lifetime warranty policies: complexities in modelling and industrial application. In: Proceedings of the fifth Asia-Pacific industrial engineering and management systems conference, Gold Coast, Australia, 12-15 December; 2004. p. 249.

[7] V. Padmabhaban and R.C. Rao, Warranty policies and extended service contract: theory and an application to automobiles, Mark Sci 12 (1993), pp. 230-247.

[8] G.N. Chattopadhyay and D.N.P. Murthy, Warranty cost analysis for second-hand products, Math Comput Modelling 31 (10-12) (2000), pp. 81-88.

[9] G.N. Chattopadhyay and D.N.P. Murthy, Cost sharing warranty policies for second-hand products, Int Trans Oper Res 8.1 (2001), pp. 47-60.

[10] G.N. Chattopadhyay and D.N.P. Murthy, Optimal reliability improvement for used items sold with warranty, Int J Reliab Appl 5 (2) (2004), pp. 47-57.

[11] E. Ashgarizadeh and D.N.P. Murthy, Service contract: a stochastic model, Math Comput Modelling 31 (2000), pp. 11-20.

[12] W.R. Blischke and D.N.P. Murthy, Reliability: modeling, prediction, and optimization, Wiley, New York (2000).

[13] C.E. Wells, Determining the future costs of lifetime warranty, IIE Trans 19 (2) (1985), pp. 178-181.

[14] R. Barlow and L. Hunter, Optimum preventive maintenance, Oper Res 8 (1960), pp. 90-100. 